\title{
MEASUREMENT OF OBJECTIVE FUNCTION FOR BLDC MOTOR OPTIMIZATION
}

\author{
Peter BOBER \\ Department of Electrical Engineering and Mechatronics, Faculty of Electrical Engineering and Informatics, \\ Technical University of Košice, Letná 9, 04200 Košice, Slovak Republic, Tel.: +421 55602 2281, E-mail: peter.bober@tuke.sk
}

\begin{abstract}
The design of electrical motors is founded on an inventive idea which creates basic motor structure. Then optimization of dimensions and other parameters follows. Finally, a control or switching strategy can be optimized. This article describes a measurement of an objective function for BLDC motor control optimization. Namely measurement of no load speed and current, efficiency estimation, and noise as a function of the current commutation angle is described. The commutation angle is usually derived from Hall sensors, and its correct value is important for high efficiency and other motor characteristics. Experimental measurements show how speed, current, efficiency, and noise spectrum depends on commutation angle. Presented measurements are primarily intended for in situ optimization of commutation angle on running motor.
\end{abstract}

Keywords: BLDC motor, optimization, objective function, efficiency, noise

\section{INTRODUCTION}

Electric motors are an essential part of a growing number of devices. The motor design has been evolving for almost two hundred years. Although there are thousands and thousands of electric engines differing in size and structural arrangement, basic types are just a few. Only certain types prevail at different times and for different purposes. In the beginning, it was a DC commutator motor. AC induction and synchronous motors gained importance with the rise of the alternating current dominance. However, DC motors remained where speed or torque regulation was needed. The arrival of advanced semiconductors gradually wiped off differences between motors with and without regulation. Therefore, AC motors pushed DC motors out of their position. Industrial production of rare earth permanent magnets has brought a new change in the situation and a stand-out of permanent magnet machines. However, reluctance motors with the advantage of simpler and cheaper construction competed with permanent magnet machines. The need to use electronics for switching phase currents in reluctance motors is no longer any technical or economical issue.

BLDC (Brushless Direct Current) motor construction resembles the synchronous machine with permanent magnets but originates from brushed DC motor. It is powered by a DC voltage and phase current commutation is done electronically. Its characteristics are similar to those of the DC motor with commutator and speed can be controlled by varying the supply voltage. The industrial use of the BLDC motors begun when the price of electronics had been balanced by operational benefits: low noise, reliability, high efficiency, ease to control, and zero maintenance. The term BLDC motor is sometimes used for a broader group of motors fed by the inverter from DC supply, including, for example, reluctance motors.

BLDC motors range in size from small instrumental motors to hundreds of $\mathrm{kW}$. Their field of application is very broad: computer fans, hard disks, the white goods, CNC machines, industrial robots. They also serve as traction motors for driving electric bicycles, road vehicles, trams, and locomotives. Although BLDC motors with permanent magnets are valued higher regarding their power density and efficiency to induction and reluctance motors, their dominance is not clear. For example, in each of the following three types of electric cars, different engines are used. Volkswagen e-Golf is powered by an 85kW EEM-85 synchronous permanent magnet AC motor [1]. Land Rover Defender 110 is powered by propulsion SR Drive ${ }^{\circledR}$ with the rated power of $70 \mathrm{~kW}$, what is a switched reluctance motor [2], and famous Model S (Tesla Motors) uses an induction motor [3].

In recent years, several studies have compared and recommended various motor types for electric vehicle powertrains ([4] - [9]). The authors [4] recommended AC motor with permanent magnets due to high torque and efficiency. A comparison of the characteristics in [5] shows that a permanent magnet motor has a higher torque and greater overall efficiency than an induction motor. Losses in induction motors are 2-3\% higher, but the current price is only half of the price of permanent magnet motors. Various modes of engine operation are compared in [6], and the authors recommend the use of induction motors because of a lower price. Increased losses can be compensated by higher battery capacity.

As following from the abovementioned, no drive has such properties as to be the preferred choice and everything depends on further development. The Department of Electrical Engineering and Mechatronics (DEEM) at the Technical University of Košice is working on several projects related to BLDC motors. It cooperates with manufacturers of motors for white goods that use permanent magnet brushless motors and reluctance motors [10]. Important is the economic aspect in this case. Price reduction can be achieved by removing the rotor position sensor, the function of which is replaced by a more complex control algorithm. Another partner of DEEM is a manufacturer of robot gearboxes with integrated motors and a power converter. Here, small dimensions, positioning accuracy and high dynamic range of the entire drive are critical [11].

One area of research is optimal motor control. To run a BLDC motor an electronic switching circuit which commutate currents from one phase winding to another is required. A switching angle is derived from position sensors (e.g. Hall sensors) or is calculated from a 
measurement of phase voltages and currents in case of sensorless motor control. Due to its simplicity, a motor control with Hall sensors is often used for low-cost mass production. A correct angle for current commutation is crucial for proper motor operation. It influences motor torque, efficiency, torque ripple, and noise as is demonstrated in [12], [13] and [14]. Therefore evaluation and compensation of misplacement of Hall sensors was investigated by many researchers. Authors in [13] identify the Hall sensor angle misplacement by determining when the back EMF on floating phase crosses zero. In the case of ideal positioning, it is in the middle between two moments of current switching. A similar method was utilized in [12] where the motor has been rotated by a prime mover and zero crossing of line-to-line back EMF voltage was measured. Authors in [15] accepted misplacement of sensors in a motor production and suggested self-compensation of commutation angle based on dc-link current. The difference value of dc-link currents before and after the commutation instant equals to zero when the commutation instant is ideal. Another approach is used in [16]. The position error value is divided into relative position error of individual sensors and absolute position error. The errors are compensated separately. The relative position error of individual sensors is corrected by the least square method from Hall sensor signal edge sequence. Corrected switching angles are regularly displaced by $60^{\circ}$. The absolute error means shifting all sensors by the same angle. This error is compensated by back EMF zero crossing detection.

This article brings a different approach to compensate Hall sensor misalignment. The main idea is based on the fact that the sensor position error degrades one or more BLDC motor characteristics such as efficiency or a noise level. If the motor characteristics are measured than an appropriate optimization method can correct the position misalignment and maximize or minimize selected objective function. The advantage is that no special motor model is needed and the "black box" approach is used.

This article describes the measurement of several objective functions for BLDC motor switching angle optimization.

\section{OBJECTIVE FUNCTION FOR BLDC MOTOR CONTROL OPTIMIZATION}

Optimal design of a motor control algorithm requires objective functions. The basic objective functions influenced by motor control are:

- efficiency and power density,

- torque/speed characteristics,

- speed range.

There are other objective functions which are important for different application areas:

- torque ripple,

- noise (acoustic spectrum),

- electromagnetic compatibility,

Further criteria for decision making for a mass production are:

- cost,
- failure rate,

- maintenance costs,

- operating temperature.

A multi-objective optimization which combines several objective functions is commonly used for a practical design [17].

The objective function can result from a mathematical model as a mathematical expression, or it is calculated from a numerical model, or the objective function value is the result of an experimental measurement.

The objective function is influenced by design variables which are free to be adjusted. Selection of design variables depends on a type of optimization task. In the case of motor control, design variables are:

- switching strategy of phase winding voltage,

- controller type,

- controller parameters.

The switching strategy, controller type, and its parameters can be modified on the fly even with the real motors. In such case, in situ measurement on running motor is needed. This approach is used in [18] where accurate knowledge of some of the induction motor parameters is crucial to implement efficient control schemes and to in situ efficiency determination without performing a no-load test.

This article describes the measurement of two objective functions on running BLDC motor. Namely:

- calculated efficiency,

- acoustic spectrum.

Selected objective functions were measured according to the design variable that is a shift of commutation angles from the standard position given by Hall sensors of the motor.

\section{MEASUREMENT EQUIPMENT}

Block diagram of the measurement system is in Fig. 1. BLDC motor is powered from a DC power supply through the inverter L6234, which is controlled by digital signal processor TMS320F28335. Processor operating frequency is $150 \mathrm{MHz}$. It contains a 12-bit $\mathrm{AD}$ converter with a conversion time of 80 ns. Measurement unit placed between inverter and motor measure voltage and current of phase windings. Total supply current is measured by a digital multimeter. The rotor position and speed is measured by an incremental encoder (IRC) with a resolution of 4000 increments per revolution. Hall sensors (Hall) are used as low-resolution absolute position sensors for commutation angle determination. A noise of the motor is sensed by a microphone (Mic). All voltage, current and position data are transferred to Data Acquisition and Analysis Software running on PC.

Measurements were carried out on the BLDCMOT2454 motor from MotorSolver. It is a $250 \mathrm{~W}$ three-phase BLDC motor with a nominal voltage of $42 \mathrm{~V}$, current $5.7 \mathrm{~A}$, and nominal speed is of $3600 \mathrm{rpm}$. The rotor has five pole-pairs. 


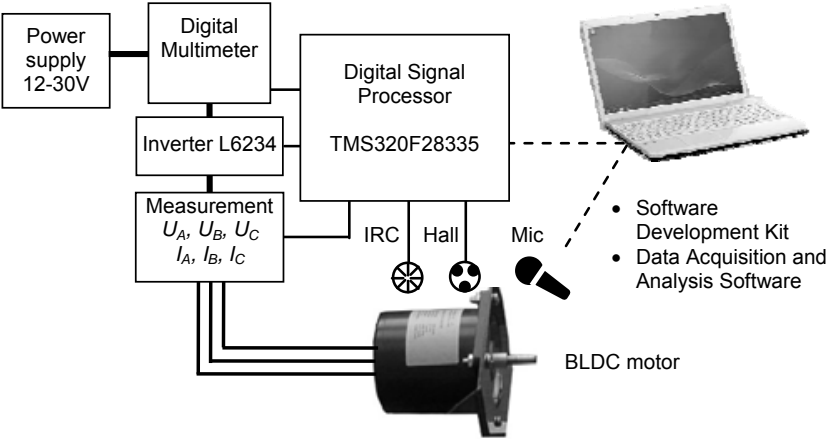

Fig. 1 Measurement equipment

\section{BLDC MOTOR CONTROL}

Without the electronics, the BLDC motor cannot be operated. Fig. 2 shows three-phase bridge connected to BLDC motor with Hall sensors. The simplest method to drive the motor is to switch phase voltage on and off according to the commutation sequence from Table 1. Position in the table is determined by Hall sensor signals depicted in Fig. 3. One mechanical rotation consists of five electrical cycles. Six commutation per electrical cycle occurs at angles $\alpha_{0}$ to $\alpha_{5}$. The total number of commutation angles is 30 per mechanical revolution. A simple look-up table algorithm is used to drive the motor. The speed is set by changing DC power supply voltage like for a conventional DC motor.

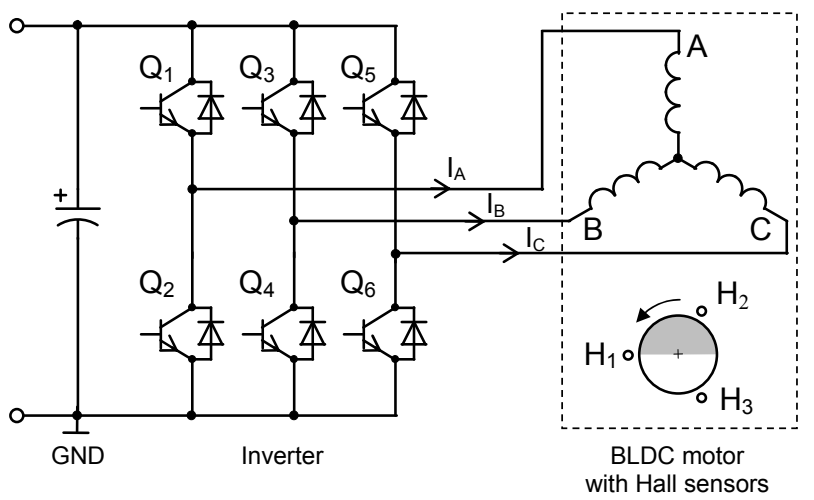

Fig. 2 Three-phase bridge connected to BLDC motor with Hall sensors

Table 1 Switching sequence in forward motor direction

\begin{tabular}{|c|c|c|c|c|c|c|}
\hline $\mathrm{H}_{1} \mathrm{H}_{2} \mathrm{H}_{3}$ & 110 & 100 & 101 & 001 & 011 & 010 \\
\hline $\mathrm{Q}_{1} / \mathrm{Q}_{2}$ & off / off & on / off & on / off & off / off & off / on & off / on \\
\hline $\mathrm{Q}_{3} / \mathrm{Q}_{4}$ & on / off & off / off & off / on & off / on & off / off & on / off \\
\hline $\mathrm{Q}_{5} / \mathrm{Q}_{6}$ & off / on & off / on & off / off & on / off & on / off & off / off \\
\hline
\end{tabular}

\section{EXPERIMENTAL MEASUREMENT}

This section describes experimental measurement on the motor with presented measurement equipment. First, a measurement of a standard operational state is described. Then, a measurement of objective function, namely no load speed and current, efficiency estimation, and noise, is following.

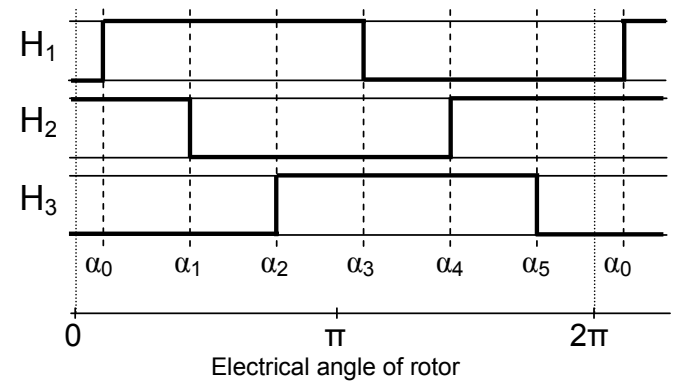

Fig. 3 The sequence of Hall sensor signals for one electrical cycle

\subsection{Measurement of phase currents and voltages}

The measurements of phase currents and phase to common ground voltages for one electrical cycle are in Fig. 4. The figure illustrates a standard operational state of the three-phase BLDC motor. Current commutation occurs every 60 electrical degrees. DC power supply voltage is $12 \mathrm{~V}$. Phase currents are measured by ACS712TELC-05B, isolated Hall Effect-Based Linear Current Sensor IC connected to the processor AD converter. Phase to common ground voltages (GND in Fig. 2) are connected to the processor through a voltage divider and RC filter. A sample period of measurement is $250 \mu \mathrm{s}$.

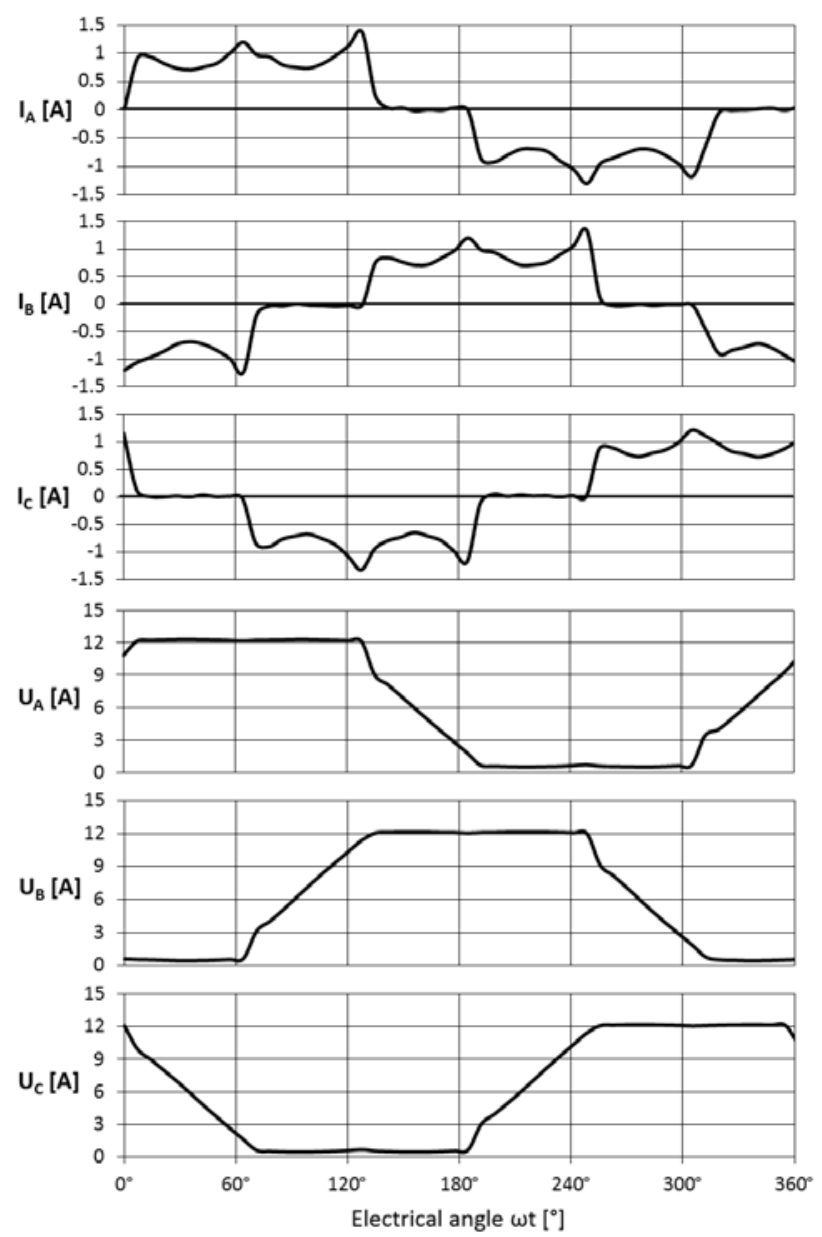

Fig. 4 Phase currents and phase to common ground voltages measurement for one electrical cycle $(12 \mathrm{~V}, 923 \mathrm{rpm})$ 


\subsection{Design variable}

Commutation angles of phase currents are determined by signals from the Hall sensors. Deviation from the ideal position can change efficiency and other characteristics of the motor. Therefore, the common shift angle $\alpha$, which is added to $\alpha_{0}, \alpha_{1}, \alpha_{2}, \ldots, \alpha_{5}$ from Fig. 3 , is selected as one of possible design variables. It represents a mechanical shift of Hall sensor placement. The shift is performed by software by addition $\alpha$ to the original signal position measured by the incremental encoder.

\subsection{Motor efficiency estimation}

The motor efficiency is estimated from measurement of motor speed, current, and supply voltage. This approach is chosen with the intention to calculate efficiency directly by a controller in situ operation of the motor in future applications. In such case, no special torque measurement device is presented.

Motor power efficiency $\eta$ is:

$\eta=\frac{P_{2}}{P_{1}}$

where: $P_{1}-$ electric input power, $P_{2}-$ mechanical output power. Electric power is the product of the supply voltage $U$ and the total current $I$ from DC power supply.

$P_{1}=U I$

Assume that the unloaded motor is braked only by friction torque $M_{\mathrm{t}}$, which is approximately constant and independent of the motor speed. Then the mechanical power $P_{2}$ is proportional to angular velocity $\omega$ :

$P_{2}=M_{t} \omega=M_{t} 2 \pi \frac{n}{60}$

where $n$ is motor speed in rpm. Now equations (2) and (3) are plugged back into (1):

$\eta=\frac{P_{2}}{P_{1}}=\frac{M_{t} 2 \pi \frac{n}{60}}{U I}=\frac{M_{t} 2 \pi}{60 U} \cdot \frac{n}{I}$

Provided that voltage $U$ is maintained constant by DC power supply and $M_{\mathrm{t}}$ is constant, too, the equation for efficiency index $E$, which is proportional to the efficiency $\eta$, can be formulated:

$$
E=\frac{n}{I}
$$

Fig. 5 and Fig. 6 show measurement of no load speed and current of the motor for different DC power supply voltage $U$ and common shift angle $\alpha$ in the range of $-7.2^{\circ}$ to $4.5^{\circ}$. The change of motor speed $n$ is small enough to accept the premise that the torque $M \mathrm{t}$ is constant for defined measurement range and for given DC voltage.

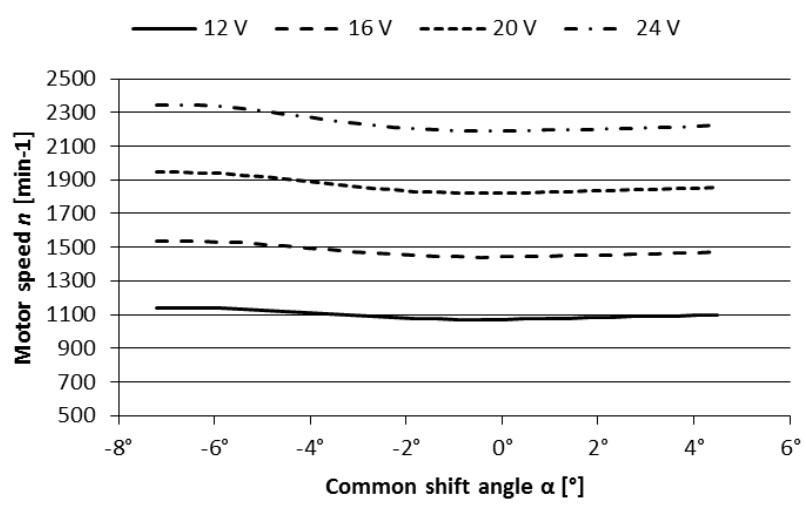

Fig. 5 Influence of common shift angle $\alpha$ on no load speed of the motor at different power supply voltages

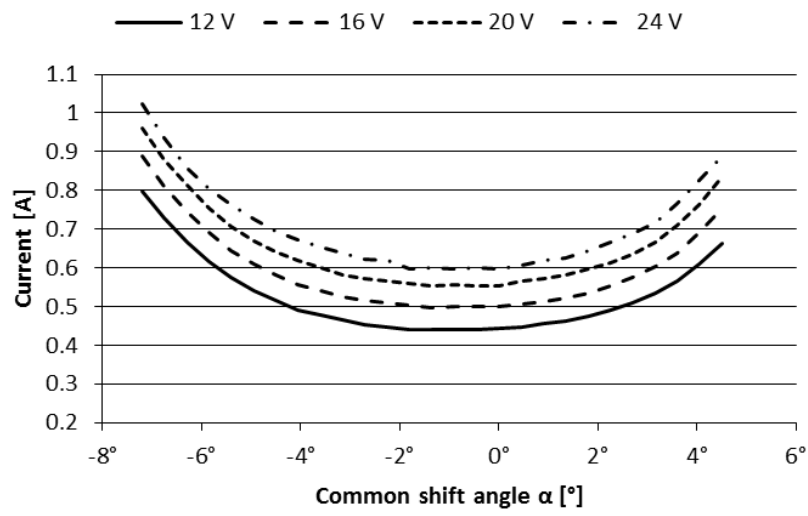

Fig. 6 Influence of common shift angle $\alpha$ on the current of the motor at different power supply voltages

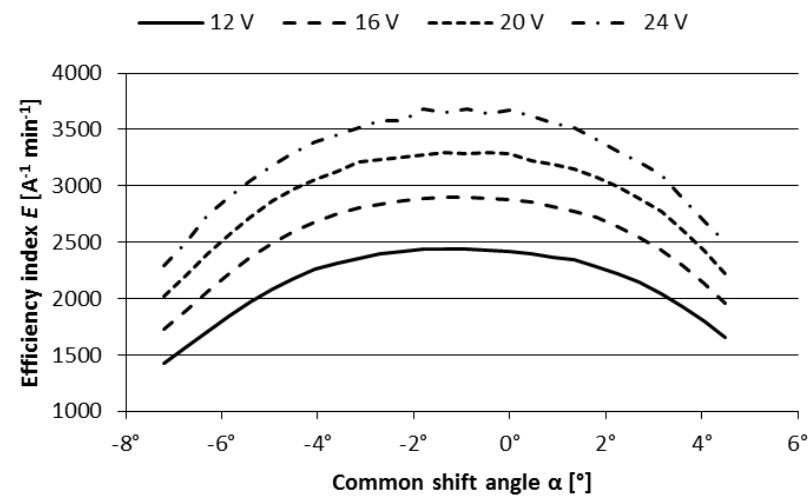

Fig. 7 Efficiency index $E$ vs. common shift angle $\alpha$ at different power supply voltages

Fig. 7 shows measurement of efficiency index $E$ (objective function) which depends on common shift angle $\alpha$ (design variable).

\subsection{Noise measurement}

The acoustic noise was recorded with a microphone placed approximately at distance of $10 \mathrm{~cm}$ from the motor. Fig. 8 shows Power Spectral Density calculated from Fast Fourier Transformation. The value of Power Spectral Density on $\mathrm{Y}$ axis is only informative because no calibration of recording apparatus was done. Noise level is 
influenced by common shift angle $\alpha$. The value $\alpha=-1.8^{\circ}$ subjectively brings the least disruptive noise.

Several relevant frequencies are marked in Fig. 8. Mechanical speed $2184 \mathrm{rpm}$ (24V supply voltage) creates power peak at frequency $36.4 \mathrm{~Hz}$. Cogging torque of five pole-pairs creates a peak at ten times higher frequency 364 $\mathrm{Hz}$. Frequency $1093 \mathrm{~Hz}$ is created by switching of currents 30 times per mechanical revolution. There are another noise sources as bearings and aerodynamic sources which do not depend on commutation angle directly [19].

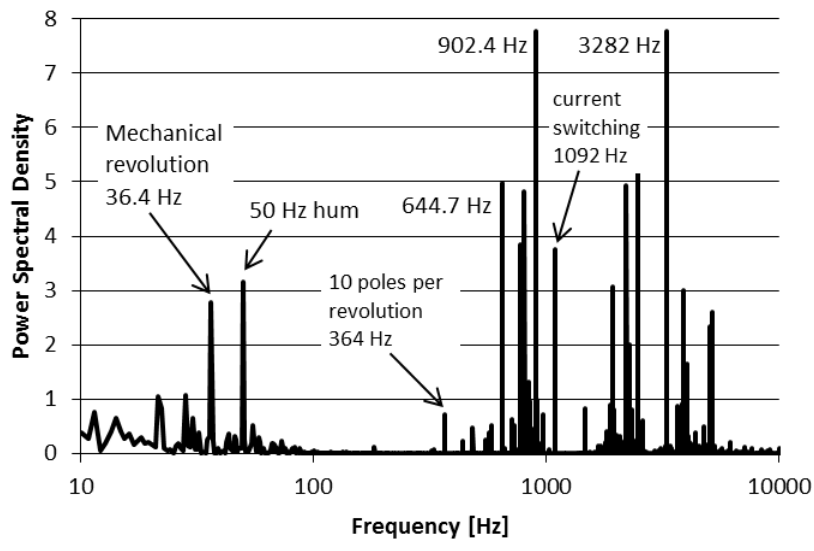

Fig. 8 Power spectral density of the acoustic signal, $\alpha=-1.8^{\circ}$

Comparison of noise spectrum for "silent" $\left(-1.8^{\circ}\right)$ and "noisy" $\left(3.6^{\circ}\right)$ shift angle $\alpha$ is in Fig. 9. The noisy sound has more energy at higher frequencies than at low ones. The division of power between three bands for each angle $\alpha$ is shown in Fig. 10, and Fig. 11 shows total signal energy for different shift angles $\alpha$. A minimum energy lies between $-1.8^{\circ}$ and $-3.6^{\circ}$ which means that actual build in Hall sensor placement is not optimal. The differences found can be used for correct setting of shift angle by appropriate optimization method. Either minimizing high band energy or total signal energy can be used.

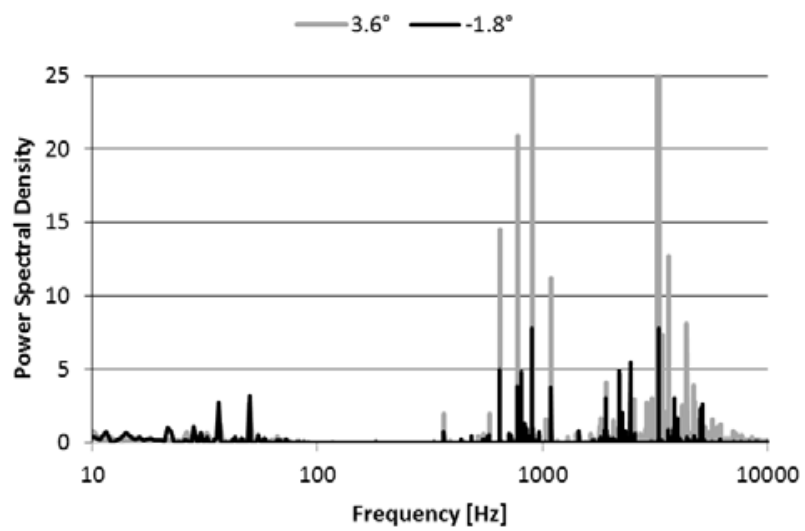

Fig. 9 Power spectral density of the acoustic signal, $\alpha=-1.8^{\circ}$

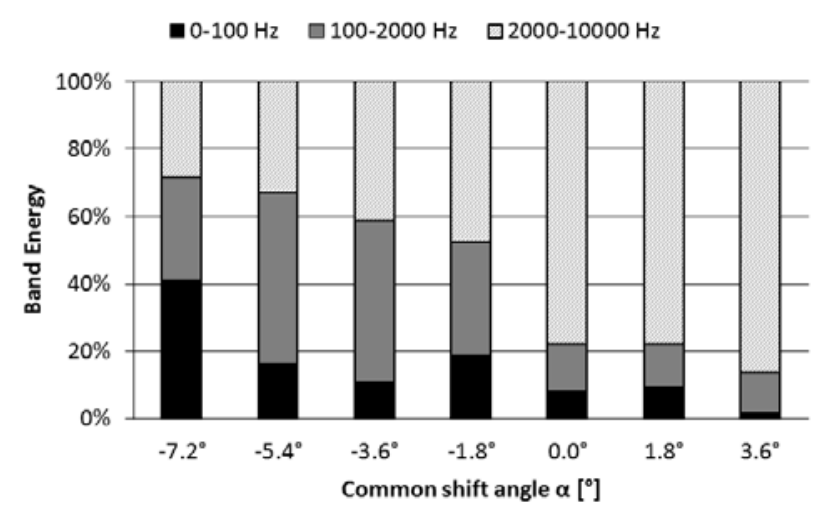

Fig. 10 Signal energy distribution between bands for different common shift angle $\alpha$

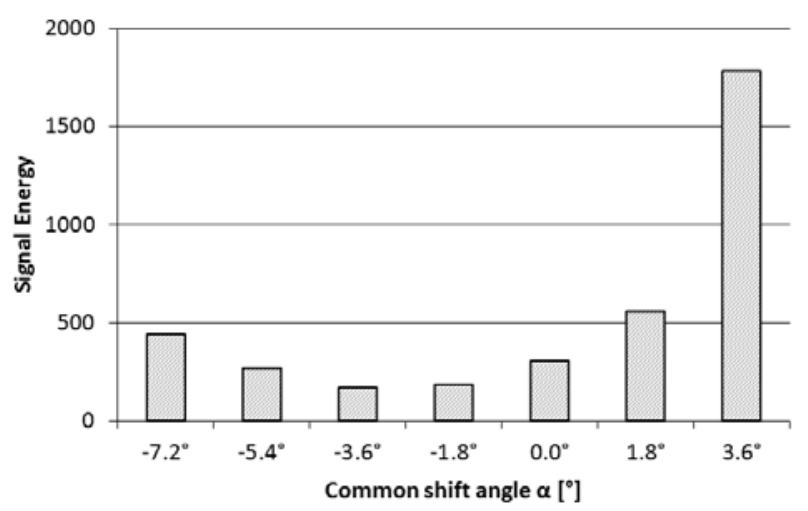

Fig. 11 Total signal energy for different shift angles $\alpha$

\section{CONCLUSIONS}

Optimal design of a motor construction or optimal control of motor requires an objective function. The paper presents the experimental measurement of two objective functions suitable for in situ measurement on a running motor. Measurement of no load speed and current, efficiency estimation, and noise as a function of the electric current commutation angle shift from a position given by Hall sensor is described. The efficiency is estimated by efficiency index which is derived from speed and current measurement, and no special torque measurement device is needed. Experimental measurements show that efficiency index, and noise spectrum energy have one global extreme. Therefore the gradient method is a good candidate to perform the angle shift optimization. Measurement revealed that Hall sensors are misplaced. The angle shift lies between $-1.8^{\circ}$ and $-3.6^{\circ}$ and the proposed measurement can be used for in situ optimization of commutation angle of BLDC motor. Optimization method will change parameters of the motor control algorithm on the fly until the optimal regime is achieved. Measurement is straightforward and does not need a special equipment. Disadvantage of using proposed measurement for the intended purpose is the need to ensure that the objective function value depends only on design variable. 


\section{ACKNOWLEDGMENT}

This material is based upon work supported by the grant VEGA 1/0464/15 of Scientific Grant Agency of the Ministry of Education, Science, Research and Sport of the Slovak Republic.

\section{REFERENCES}

[1] Volkswagen E-Golf Promises Everyday Versatility with Zero Tailpipe Emissions and Low Ownership Costs. Volkswagen Media Centre, May 12, 2014, [Online] Available at: http://media.vw.com/release/ 751/ [Accessed: 18-Jan-2017].

[2] Nidec SR Drive ${ }^{\circledR}$ motors power new Land Rover, Srdrives.com, [Online] Available at: http://www.srdrives.com/land-rover.shtml

[Accessed: 16-June-2016].

[3] RIPPEL, W.: Induction Versus DC Brushless Motors. Teslamotors.com, January 9, 2007, [Online] Available at: https://www.teslamotors.com/en_EU/ blog/induction-versus-dc-brushless-motors [Accessed: 16-June-2016].

[4] GRILO, N. - SOUSA, D. M. - ROQUE, A.: AC motors for application in a commercial electric vehicle: Designing aspects, 16th IEEE Mediterranean Electrotechnical Conference, Yasmine Hammamet, pp. 277-280, 2012.

[5] GUAN, Y. - ZHU, Z. Q. - AFINOWI, I. A. A. MIPO, J. C. - FARAH, P.: Comparison between induction machine and interior permanent magnet machine for electric vehicle application, COMPEL: The International Journal for Computation and Mathematics in Electrical and Electronic Engineering, Vol. 35, No. 2, pp. 572-585, 2016.

[6] BURWELL, M. - GOSS, J. - POPESCU, M.: Performance/cost comparison of induction-motor \& permanent-magnet-motor in a hybrid electric car, July 2013, International Copper Association, Tokyo, [Online] Available at: http://www.coppermotor. com/wp-content/uploads/2013/08/Techno-Frontier2013-MBurwell-ICA-EV-Traction-Motor-

Comparison-v1.8-Eng1.pdf [Accessed: 16-June2016].

[7] DORRELL, D. G. - KNIGHT, A. M. - POPESCU, M. - EVANS, L. - STATON, D. A.: Comparison of different motor design drives for hybrid electric vehicles, In: 2010 IEEE Energy Conversion Congress and Exposition, Atlanta, GA, pp. 3352$3359,2010$.

[8] YILDIRIM, M. - POLAT, M. - KURUM, H.: A survey on comparison of electric motor types and drives used for electric vehicles, In: 16th International Power Electronics and Motion Control Conference and Exposition (PEMC), 21-24 September 2014, Antalya, Turkey, pp. 218-223.

[9] PENIAK, A. - MAKAROVIČ, J. - RAFAJDUS, P.: Replacing of DC motor in the first Slovak electric car by an optimized switched reluctance motor, 2016 ELEKTRO, Strbske Pleso, pp. 350-354, 2016, http://dx.doi.org/10.1109/ELEKTRO.2016.7512095

[10] SUCHÝ, L. - FERKOVÁ, Ž.: Simulácia elektrického pohonu so spínaným reluktančným motorom, Strojárstvo, Vol. 20, No. 4, pp. 98-99, 2016.

[11] FEDAK, V. - DUROVSKY, F. - UVEGES, R. KYSLAN, K. - LACKO, M.: HIL simulator of drives of an industrial robot with $6 \mathrm{DOF}$, Elektronika ir Elektrotechnika, Vol. 21, No. 2, pp. 14-19, 2015, http://dx.doi.org/10.5755/j01.eee.21.2.11506

[12] ALAEINOVIN, P. - CHINIFOROOSH, S. JATSKEVICH, J.: Evaluating misalignment of hall sensors in brushless DC motors, 2008 IEEE Canada Electric Power Conference, Vancouver, BC, 2008, pp. 1-6, http://dx.doi.org/10.1109/EPC.2008.4763 350

[13] TSOTOULIDIS, S. - SAFACAS, A.: Side-effects of Hall sensors misplacement on BLDC motor drive operation, 2014 International Conference on Electrical Machines (ICEM), Berlin, pp. 1825-1830, 2014, http://dx.doi.org/10.1109/ICELMACH.2014. 6960431

[14] SIKORA, A. - ZIELONKA, A. - KULESZ, B.: Impact of Hall sensors positioning on symmetry of BLDC control signals, International Symposium on Power Electronics Power Electronics, Electrical Drives, Automation and Motion, Sorrento, pp. 249252, 2012, http://dx.doi.org/10.1109/SPEEDAM. 2012.6264444

[15] FANG, J. - LI, W. - LI, H.: Self-Compensation of the Commutation Angle Based on DC-Link Current for High-Speed Brushless DC Motors With Low Inductance, IEEE Transactions on Power Electronics, Vol. 29, No. 1, pp. 428-439, Jan. 2014, http://dx.doi.org/10.1109/TPEL.2013.2254499

[16] PARK, J. S. - CHOI, J-H. - LEE, J.: Compensation Method of Position Signal Error with Misaligned Hall-Effect Sensors of BLDC Motor, J. Electr. Eng. Technol., Vol. 11, No. 4, pp. 889-897, 2016, http://dx.doi.org/10.5370/JEET.2016.11.4.889

[17] ILKA, R. - TILAKI, A. R. - ASGHARPOURALAMDARI, H. - BAGHIPOUR, R.: Design Optimization of Permanent Magnet-Brushless DC Motor using Elitist Genetic Algorithm with Minimum loss and Maximum Power Density, International Journal of Mechatronics, Electrical and Computer Technology, Vol. 4, No. 10, pp. 11691185, 2014, Available at: http://www.aeuso.org [Accessed: 24-Jan-2017].

[18] CHANDRAKANTH, S. A. - CHELLIAH, T. R. SRIVASTAVA, S. P. - THANGARAJ, R.: In-situ Efficiency Determination of Induction Motor through Parameter Estimation, In: Proceedings of the International Conference on Soft Computing for Problem Solving (SocProS 2011) December 20-22, 
2011, Volume 1, 2012, Springer India, India, pp. 689-700, http://dx.doi.org/10.1007/978-81-3220487-9_66

[19] JANDA, M. - VITEK, O. - HAJEK, V.: Noise of Induction Machines, In: Rui Esteves Araújo, ed.: Induction Motors - Modelling and Control, 558 pages, Publisher: InTech, 2012, http://dx.doi.org/ $10.5772 / 38152$

Received May 7, 2017, accepted October 24, 2017

\section{BIOGRAPHY}

Peter Bober graduated (MSc) in 1987 with distinction at the Department of Cybernetics of the Faculty of Electrical Engineering at the Technical University of Košice, Slovakia. He defended his Ph.D. in the field of induction motor control in 1993. Currently, he is teaching and doing research at the Department of Electrical Engineering and Mechatronics, Faculty of Electrical Engineering and Informatics, Technical University of Košice. His scientific research is focused on modeling, simulation, and optimization in the field of electric drives. 